\section{The waste of THORP}

The diagram (right) shows the path of spent fuel through a reprocessing plant.

In a typical reactor, roughly 30 tonnes of spent fuel elements would be withdrawn each year, after three years service. On average this spent fuel would contain one tonne of fission products, half a tonne of unburnt uranium-235 and plutonium in equal quantities, and about 0.2 tonne of uranium-236, neptunium, americium and curium. After separation, the fission product solutions have the highest radioactivity and generally also contain some of the very long-lived actinides. The fission-product activity in the 30 cubic metres or so of these solutions decays rapidly, however, and after a few hundred years has virtually disappeared; what remains is the very long-lived but low-level actinide activity.

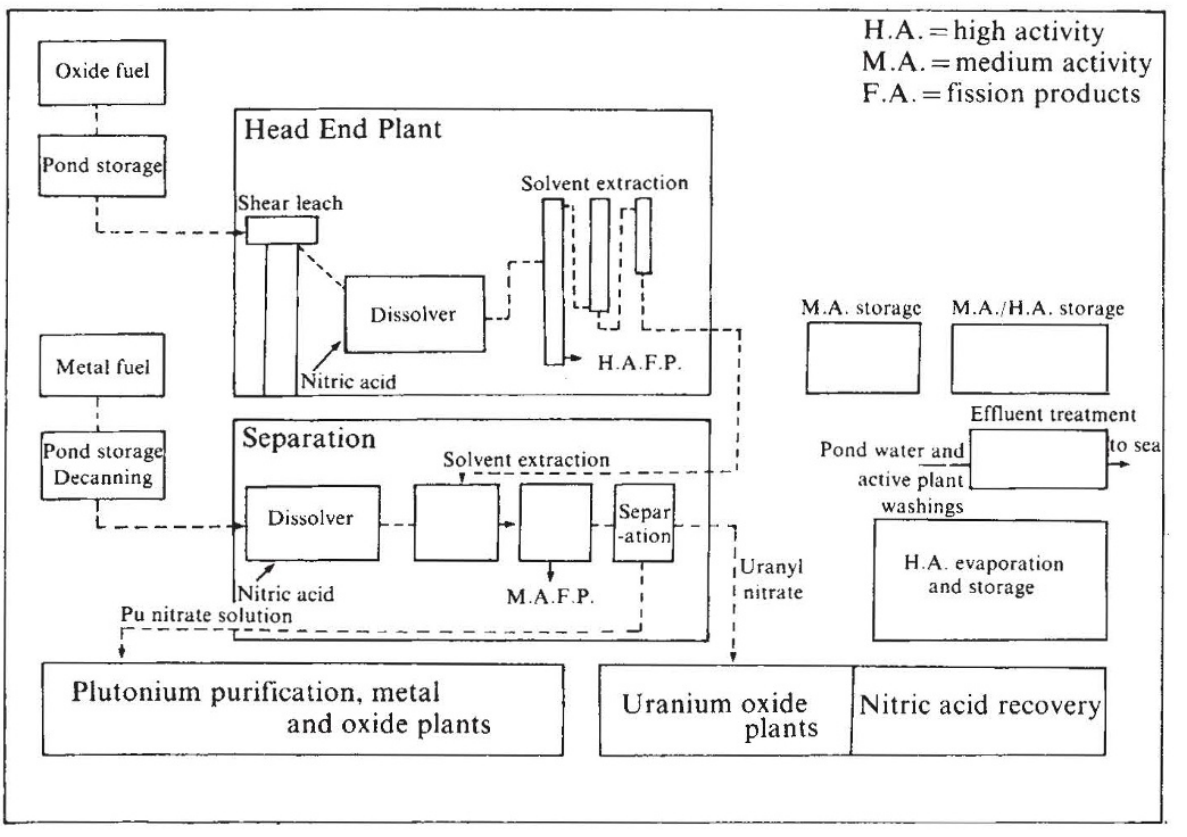

\title{
A black and white report for debate
}

Reactions to $\mathrm{Mr}$ Justice Parker's report on the proposed extension to facilities for reprocessing thermal reactor oxide nuclear fuel have varied widely. Arthur Palmer, MP, Chairman of the Select Committee on Science and Technology, for example, called it "an excellent report, far better than anticipated. . . Parker is extremely realistic - he looks on nuclear power, of which reprocessing is an integral part, as a necessity in an industrially advanced country-as I do". Robin Cook, MP, charges Parker with making selective quotations from his witnesses-and it is true that many objectors are quoted only when they are in favour of some aspect or other supporting the construction of THORP. "I am extremely concerned with the report" said Cook last week. "Parker has decided to present the case for THORP -and he's better at it than BNFL".

Cook, speaking at a briefing meeting for MPs at the House of Commons last week, said there wene alternative sources to nuclear power such as coal, oil, gas, waves, tidal barriers, wind and solar eriergy "and if we cannot squeeze a future out of that it is a very sour comment on our previous energy investment".

Palmer, an electrical power engineer, looks on it very differently. "The report is not afraid to tell the blunt truth" said Palmer. "Even if nuclear power had every risk attributed to it by its critics-which it hasn't -it would still be necessary if this country is to survive commercially and prosper". If there is low nuclear growth, Palmer believes, Britain will lose its nuclear power engineers, and the nuclear industry would be broken.
A debate on the Windscale report takes place in the House on Wednesday 22 March, following a complicated procedural move by the Secretary of State for the Environment, Mr Peter Shore, to avoid the legal complications in such a course. Mr Shore was obliged to take a decision on THORP without hearing further argument: so he refused permission for it to be built, arranged this Wednesday's debate, and is expected to lay a "special development order" before the House to grant permission after Easter. $\mathrm{Mr}$ Shore promises to take note of the "feeling". There will probably be no division.

Pressure for the debate came with an 'early day motion'-effectively an MP's petition-some weeks ago requesting a debate; it was signed by 200 MPs.

Whether that number will turn up on Wednesday is not clear at the time of writing. The following day is the last day of the session and is filled with procedural business; and many MPs return to their constituency the day hefore. The estimate of one MP who hopes to speak in the Windscale debate is that perhaps a dozen MPs in the House are sufficiently well informed to make effective contributions; and that some 40 more are interested enough to speak but have not studied the problem carefully. There should be time in the seven hours of the debate from 3.30 to $10.30 \mathrm{pm}$ for about 12 speakers on each side of the House to speak. A head-count makes it clear that the opposition to THORP, though vocal, is very small; which makes it difficult to interpnet Peter Shore's intention to take note of the debate. Will he take note of the points made and write his special development order accordingly? Or count ayes?

If he looks for spectacular speeches, then he could do no better than take note of Leo Abse, MP for Pontypool, who made a name for himself last December as a new and rhetorical star in the nuclear campaigner's firmament. Nuclear power is Abse's new concern. "One or two debates in the House of Commons do not end matters" said Abse last week. "I am used to long campaigns". Abse has been a long and successful campaigner for many reforms, particularly in the laws relating to private life-such as divorce and homosexuality. It remains to be seen how he fares with the equally emotive but highly technical matters of nuclear energy. Mr Wedgwood Benn, Secretary of State for Energy, congratulated Abse warmly for his December speech on these matters. But another observer, well briefed in nuclear matters, described it as " $30 \%$ right but $70 \%$ rubbish". We shall see.

\section{Leo Abse, MP, taking up the objectors' cause}

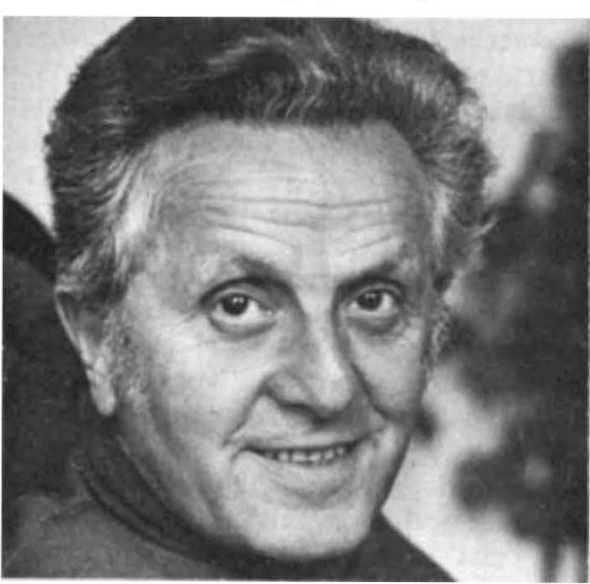

